\title{
Study the metallic finishing and corrosion control processes for carbon steel over head pipes using polymer molecules
}

\begin{abstract}
Carbon steel has wide applications in industry (especially in petroleum industry, e.g. pipelines out from the top of distillation towers (over head pipes), pressure vessels, nozzles etc.) and domestic life. Study the phenomenon of electropolishing which is important as metallic finishing process which takes place before electroplating of metal. This work is devoted to study the electropolishing of carbon steel in phosphoric acid in presence of polymers molecules (Starch, Gelatin, Agar, Chitosan, Arabic gum, Cellulose acetate, Cellulose and Carboxymethyl cellulose sodium salt). The rate of electropolishing of carbon steel in phosphoric acid solution in case of applied various affecting factors was investigated by estimated polarization curves from values of current and voltage that were obtained from the electrochemical cell. Morphology of the specimens after the experiment is monitored using scanning electron microscope (SEM). The (SEM) micrographs support the experimental measurements and give more light on carbon steel surface. Finally, samples of industrial waste water are collected from a drain of vacuum distillation tower over head pipes in Alexandria petroleum company and ferrous ions $\mathrm{Fe}^{+2}$ concentrations are determined in case of presence and absence of polymers molecules in order to judge the role of these polymers as a corrosion inhibitors on the ability to control the corrosion on carbon steel over head pipes.
\end{abstract}

Keywords: metallic finishing process, polymers molecules, carbon steel, corrosion inhibitors, cellulose acetate
Volume I Issue 5 - 2017

\author{
Hamdy FM El-shamy, ' Aggour YA,' Ahmed \\ $\mathrm{AM}^{2}$ \\ 'Department of Chemistry, Faculty of Science, Damietta, \\ University, Egypt \\ ${ }^{2}$ Department of Chemistry, Faculty of Science, Alexandria \\ University, Egypt
}

\begin{abstract}
Correspondence: Hamdy FM El-shamy, Department of Chemistry, Faculty of Science, Damietta University, Egypt, Tel
\end{abstract} +2032 2000 26, Email hamdi.alex88@yahoo.com

Received: October 16, 2017| Published: October 26, 2017
Abbreviations: $\mathrm{CMC}$, carboxymethyl cellulose sodium salt; EDS, energy dispersive x-ray spectroscopy; SEM, scanning electron microscopy; EP, electropolishing

\section{Introduction}

Electropolishing is suitable for polishing of hardened materials that are mechanically difficult to machine, because in electropolishing the electrode and the work piece are not in contact with each other. The mechanism of electropolishing is usually explained as follows: the electropolishing effect occurs because of differential dissolution, as the current is applied, the oxidization film covering the lower peaks of the surface, which has a high specific. ${ }^{1}$ In view of its strength and low cost, carbon steel is used widely as a material of construction in chemical industry to build pipelines, storage tanks, heat exchangers, pumps, etc. ${ }^{2}$ However steel suffers from corrosion in electrolytes because of the presence of cementite in its structure. ${ }^{3,4}$ Cementite $\left[\mathrm{Fe}_{3} \mathrm{C}\right]$ which does not form solid solution with iron $[\mathrm{Fe}]$ and hence leads to steel corrosion through the formation of a multitude of microscopic galvanic cells of the type :

\section{$\mathrm{Fe} /$ Electrolyte /Fe3C (Cementite)}

To protect steel structures against corrosion different techniques are used such as cathodic protection, anodic protection, coating and the use of inhibitors..$^{4-7}$ Inhibitors are materials that may be injected into the system. They plate out on the surface and inhibit the formation of corrosion cells. They are commonly used in pipelines and other vessels that will contain materials that are corrosive. ${ }^{8,9}$ Some metals, such as gold and platinum, corrode very slowly or not at all. Choosing a corrosion resistant material can reduce the rate of corrosion. They are sometimes injected into the water stream that may be used for the surface preparation of steel, as in the case of water jetting. In the formulation of some primers inhibitive pigments are used. These inhibitive pigments inhibit, or interfere, with the corrosion process.

To improve the protective efficiency of carbon steel corrosion in corrosive environment, great efforts have been put into the investigation and lots of technologies have been used. The inhibitive power of the organic inhibitors has been interpreted in term of many different characteristics such as molecular size, molecular weight, molecular structure, nature of heteroatom present in the molecule, their affinities to get adsorbed on the metal surface, etc. ${ }^{10}$ A good number of the efficient corrosion inhibitors are organic compounds that contain nitrogen, oxygen, sulfur, phosphorus, and multiple bonds or aromatic rings in their structures. ${ }^{11}$ The molecular electronic structures and electron densities around these functional groups are the key structural features that determine the effectiveness of inhibition (i.e. specific interaction between functional groups and metal surface and heteroatom like $\mathrm{N}, \mathrm{O}$ and $\mathrm{S}$ play an important role in inhibition due to the free electron pairs which they possess). When both of these features combine, increased inhibition can be observed. ${ }^{12}$

Polymers as acorossion inhibitors were studied in this work. The inhibiting action of these natural polymers is usually attributed to their interaction with carbon steel surface via their adsorption. Polar functional groups are regarded as the reaction center that stabilizes the adsorption process. In general, the adsorption of inhibitor on metal surface depends on the nature and the surface charge of the metal, the adsorption mode, its chemical structure and the type of electrolyte solution. ${ }^{13}$ The aim of the present work is to study the effect of natural 
polymers namely starch, gelatin, agar, chitosan, cellulose acetate, cellulose and carboxymethyl cellulose sodium salt on the rate of electropolishing of carbon steel

A great deal of work has been directed to study the mechanism of electropolishing as well as establishing the optimum polishing conditions. Studies have revealed that electropolishing is a diffusion controlled process and its efficiency is determined by rate factors. Knowledge of the reaction kinetics is essential for the most economic utilization of the process

The rate of electropolishing of carbon steel in phosphoric acid solution in absence and presence of polymers molecules was studied in this article by measuring the limiting current of electropolishing under natural convection condition as a function of electrode height, phosphoric acid concentrations, different concentrations of polymers molecules and temperature, in order to indicate the role of polymers molecules on carbon steel electropolishing and to correlate the activation parameters. Dimensional analysis was investigated to correlate mass transfer during electropolishing reaction in presence of polymers under forced convection condition (by using rotating cylinder electrode RCE). Physical properties of solution such as density and viscosity were studied. ${ }^{14}$

\section{Experimental procedure}

\section{Chemicals}

Five different $\mathrm{H}_{3} \mathrm{PO}_{4}$ concentrations were used, namely 4, 6, 8, 10 , and $12 \mathrm{M}$, all solutions were prepared using A.R grade chemical. Blank solution $\left(8 \mathrm{M} \mathrm{H}_{3} \mathrm{PO}_{4}\right)$ was prepared as well as in presence of different concentrations from the polymers in the range of concentration (100-800ppm). The limiting current was determined at four different temperatures $298,303,308$ and $313 \mathrm{~K}$. The polymers selected in the present work are Starch, Gelatin, Agar, Chitosan, Arabic gum, Cellulose acetate, Cellulose and Carboxymethyl cellulose sodium salt (CMC) supplied by SIGMA-ALDRICH Chemicals Ltd (Table 1). The choice of the polymers molecules is based on the following considerations:
i. Natural products
ii. Non-toxic compounds
iii. Low price
iv. Easy available
v. Environmentally friendly compounds

Table I Analysis of carbon steel specimens composition (wt \%)

\begin{tabular}{ll}
\hline Components & wt\% \\
\hline $\mathrm{C}$ & 0.2 \\
$\mathrm{~S}$ & 0.04 \\
$\mathrm{Mn}$ & 2.6 \\
$\mathrm{P}$ & 0.039 \\
$\mathrm{Si}$ & 0.36 \\
$\mathrm{Fe}$ & $96.76 \mathrm{I}$ \\
Total & 100 \\
\hline
\end{tabular}

\section{Measurements of the limiting current}

The limiting current was determined by polarization curves were plotted by increasing the cell current stepwise and measuring the corresponding steady state anode potential. ${ }^{14,15}$ Anode potential was measured against a reference steel electrode placed in the cup of luggin tube whose tip is placed $0.5 \mathrm{~mm}$ from the anode surface. The potential difference between the anode and the reference electrode was measured by voltmeter. The temperatures were regulated by placing the cell in a constant $\pm 0.05^{\circ} \mathrm{C}$ ultra thermostat. The rate of electropolishing of carbon steel was determined at 25, 30, 35 and $40^{\circ} \mathrm{C}$. Polarization curves were constructed for Starch, Gelatin, Agar, Chitosan, Arabic gum, Cellulose acetate, Cellulose, Carboxymethyl cellulose sodium salt (CMC) acid mixtures at different concentrations.

\section{Surface finish morphology measurement}

The surface finish after EP was characterized using scanning electron microscopy (SEM). The SEM images were taken using a JEOL, JSM-5300, scanning microscope, OXFORD instrument. SEM is one of the most widely used analytical tools, due to the extremely detailed images it can provide. Coupled to an auxiliary Energy Dispersive X-ray Spectroscopy (EDS) detector, this technique also offers elemental identification of nearly the entire periodic table. The Scanning Electron Microscope (SEM) is a microscope that uses electrons rather than light to form an image. The SEM has a large depth of field, which allows a large amount of the sample to be in focus at one time. The SEM also produces images of high resolution, which means that closely spaced features can be examined at a high magnification. Preparation of the samples is relatively easy since most SEMs only require the sample to be conductive to not charge and deflect the electron. The combination of higher magnification, larger depth of focus, greater resolution and ease of sample observation makes the SEM one of the most heavily used instruments in research areas today. ${ }^{16}$

\section{Atomic absorption spectroscopy technique}

(Agilent-280FS AA) Atomic Absorption Spectrophotometer was used at $248.3 \mathrm{~nm}$ with Iron Hollow-Cathode Lamp to get the concentration of iron in the samples to evaluate these polymers as corrosion inhibitors. The 280FS AA is external computer-controlled atomic absorption spectrometers supporting multi element flame AA determinations using Fast Sequential analysis for improved sample throughput with flame AA. The supplies of fuel (acetylene) and oxidant shall be maintained at pressures somewhat higher than the controlled operating pressure of the instrument by suitable valves. ${ }^{17,18}$

\section{Results and discussion}

\section{Leveling process}

Leveling is the principle process in electro-polishing ${ }^{17}$ and can be explained by mass transfer mechanism. ${ }^{18}$ The study of leveling is based on the classical current voltage curves of electro dissolution. Figure $1 \& 2$ shows a typical polarization curves obtained using different concentration of electrolyte and using different electrode height. We found that the rate of electropolishing, which is represented the rate of steel corrosion in phosphoric acids decreases with increasing electrode height and electrolyte $\mathrm{H}_{3} \mathrm{PO}_{4}$ concentration. 


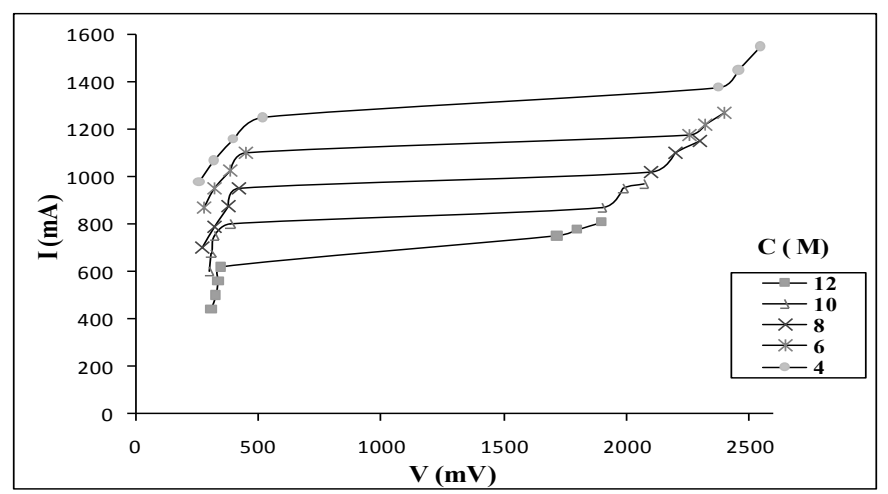

Figure I Polarization curves obtained using different concentration of electrolyte in case of undivided cell.



Figure 2 Polarization curves obtained using different electrode height in case of undivided cell.

\section{Influence of temperature and activation energy during electropolishing}

the influence of temperature on the value of the limiting current that determines the carbon steel electro polishing rate in absence and presence of different concentrations of the studied polymers in case of undivided and temperature range $298-313 \mathrm{~K}$ were studied. The influence of temperature and activation energy (Ea) of electropolishing process in presence of polymers was calculated using Arrhenius-type plot equation: ${ }^{19,20}$

$$
I \ell=A \exp \left(\frac{-E a}{R T}\right)
$$

Where A is a modified frequency factor (pre-exponential factor), Ea is the activation energy $\left(\mathrm{kJ} \mathrm{mol}^{-1}\right), \mathrm{R}$ is the gas constant $(8.314 \mathrm{~J} / \mathrm{K}$ $\mathrm{mol})$, and $\mathrm{T}$ is the absolute temperature $(\mathrm{K})$. The plot of $\ln \mathrm{I} \ell$ versus reciprocal of absolute temperature, $1 / \mathrm{T}$, gives a straight line with slope equal to $-\mathrm{Ea} / \mathrm{R}$ as shown in Figure 3 for cellulose acetate as example, from which the activation energy for the electropolishing process can be calculated. We observed that the limiting current increases with increasing temperature for different concentrations of polymers, with a consequent increase in the rate of electropolishing process of carbon steel. ${ }^{21,22}$ This increase could be explained due to:

I. The decrease of the strength of adsorption processes at elevated temperature and suggested a physical adsorption mode.

II. Increasing the temperature of the system could not augment the interaction between the metal surface and the inhibitor leading to lower surface coverage, therefore the inhibiting effect decrease. ${ }^{23}$
III. The viscosity of the solution decreases with increasing temperature with consequence increase in the diffusivity of $\mathrm{Fe}^{2+}$ according to equation (3.3)..$^{19,23}$

\section{Cellulose acetate}

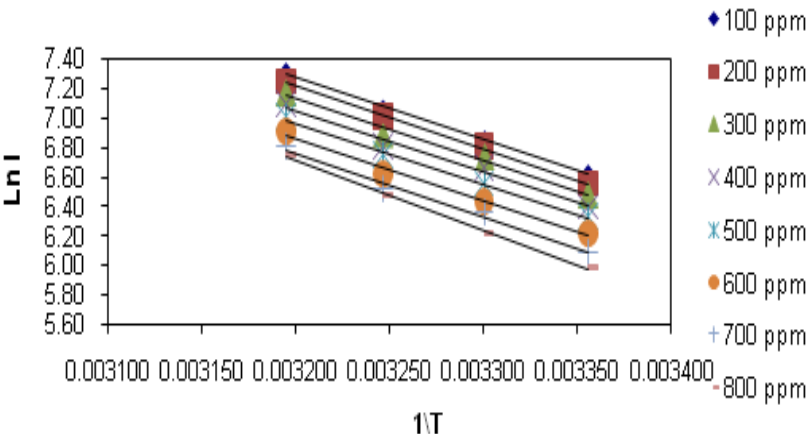

Figure 3 Arrhenius-relationship between limiting current and temperature for solution contain different polymers at different concentrations in case of undivided cell.

The activation energy of the process is an important parameter for determining the rate controlling step. If adsorption of the species on the reaction surface and subsequent chemical reaction takes place $(\mathrm{Ea})$ values usually $>43 \mathrm{~kJ} \mathrm{~mol}^{-1}$. If the rate controlling step is the diffusion of the aqueous species in the boundary layer indicating physical adsorption (Ea) is generally $\leq 43 \mathrm{~kJ} \mathrm{~mol}^{-1}$.In this work it is noted that adsorption of the species on the reaction surface in case of undivided cell were take place. ${ }^{24}$

\section{Variation in the rate within a reaction series}

Changes in either, or both, the enthalpy or the entropy of activation may be cause variation in the rate within a reaction series. The correlation of $\Delta \mathrm{H}^{*}$ with $\Delta \mathrm{S}^{*}$ is a linear relationship may be stated algebraically as: ${ }^{25}$

$$
\partial \Delta G^{*}=\frac{(1-T)}{\beta} . \partial \Delta H^{*}
$$

If follows that when $\delta \Delta \mathrm{G}^{*}$ equals zero, $(\beta)$ equals (T). In other words, the slope in a linear plots of $\Delta \mathrm{H}^{*}$ against $\Delta \mathrm{S}^{*}$ is the temperature at which all reactions that confirm to the line occur at the same rate, $(\beta)$ is therefore known as the isokinetic temperature represented in Kelvin.

Figure 4 shows that the isokinetic plot of $\Delta \mathrm{H}^{*}$ against $\Delta \mathrm{S}^{*}$ for polymers was found to be linear and the isokinetic temperatures $(\beta)$ were computed from the slopes of these plots as shown in Table 2 . Which smaller than $298 \mathrm{~K}$ indicate that the rate of the reaction is entropy control, (Starch, Agar, Arabic gum) in case of Undivided cell while which is greater than $298 \mathrm{~K}$ indicate enthalpy control reaction (Gelatin, Chitosan, Cellulose acetate, Cellulose and CMC in case of Undivided cell \& all compounds in case of divided cell ). ${ }^{26}$

\section{Adsorption isotherm}

Figure 5 shows the Flory Huggins adsorption isotherm for cellulose acetate plotted as $\log \theta / \mathrm{C}$ vs. $\log (1-\theta)$ that are reported as shown in Table 3 yielded straight line with slope $(\mathrm{x})$ and intercept $(\mathrm{xK})$ for polymers in case of using undivided cell and divided cell at $298 \mathrm{~K}$. The calculated values of $(\mathrm{x})$ and $(\mathrm{K})$ are given in Table 4 . The values of $(\mathrm{x})$ depend on the type of polymers. It is clear that the experimental data 
fits Flory Huggins adsorption isotherm (except Gelatin and Agar in case of using divided cell). The data of Table 4 reveals that, the values of (x) for (Starch, Agar, Chitosan, Arabic gum, Cellulose acetate, Cellulose and $\mathrm{CMC}$ ) in case of using undivided cell were higher than one, implied that one inhibitors molecules replace more than one water molecule at constant temperature. ${ }^{26,27}$ On other hand the other values of $(\mathrm{x})$ indicated that one inhibitor molecule replace one water molecule onto metal surface.

Table 2 Relation between $\Delta \mathrm{H}^{*}$ and $-\Delta \mathrm{S}^{*}$ at $8 \mathrm{M} \mathrm{H}_{3} \mathrm{PO}_{4}$ and $3 \mathrm{~cm}$ height for different concentrations of polymers in case of using

\begin{tabular}{|c|c|c|c|c|c|c|c|c|}
\hline \multirow{2}{*}{ Type of cell } & \multicolumn{8}{|c|}{ Isokinetic temperatures (K) } \\
\hline & Starch & Gelatin & Agar & Chitosan & Arabic Gum & Cellulose Acetate & Cellulose & CMC \\
\hline Undivided cell & 238 & 342 & 239 & 334 & 247 & 347 & 338 & 341 \\
\hline Divided cell & 380 & 353 & 367 & 331 & 349 & 338 & 336 & 330 \\
\hline
\end{tabular}

a. Undivided cell and

b. Divided cell

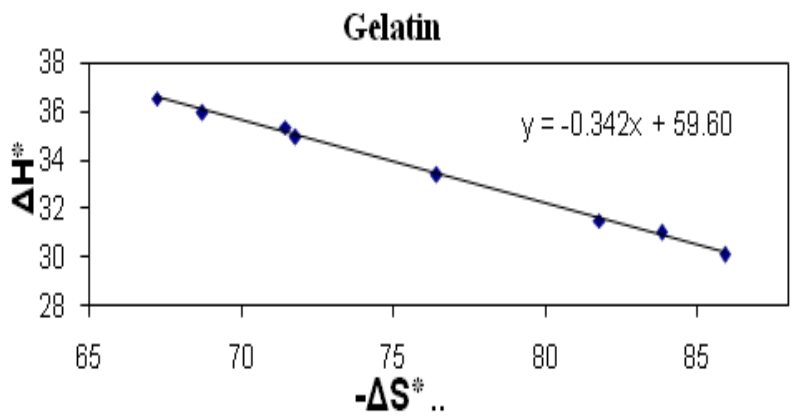

Figure 4 Relation between $\Delta \mathrm{H}^{*}$ and $-\Delta \mathrm{S}^{*}$ at $8 \mathrm{M} \mathrm{H}_{3} \mathrm{PO}_{4}$ and $3 \mathrm{~cm}$ height for different.

Cellulose a cetate

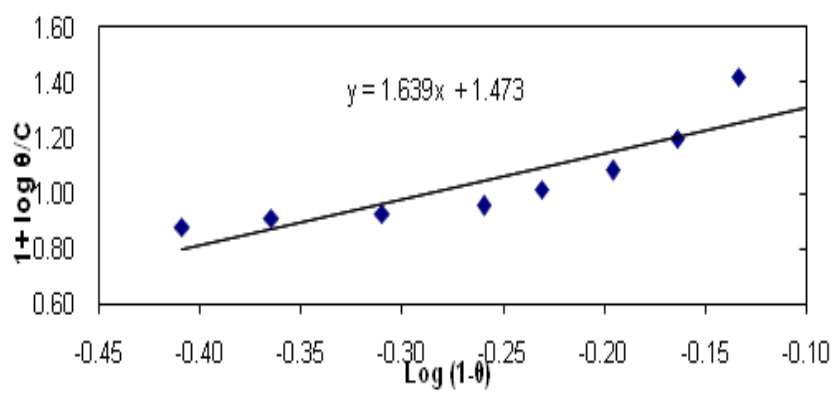

Figure 5 Flory-Huggins adsorption isotherms at 298K for Cellulose acetate.

Figure 6 shows Temkin adsorption isotherm for cellulose acetate plotted as $\theta$ vs.log C for polymers. Linear plots obtained indicating that the experimental results at all additives studies obey the Temkin adsorption isotherm. The adsorption data deduced from Temkin adsorption isotherm in case of using undivided cell are presented in Table 3. The molecular interaction parameter "a" can have both positive and a negative value indicates attraction forces between absorbed molecules. It is seen in Table 4 that the values of "a" in all cases are negative indicating that repulsion exists in the adsorption layer. It is generally known that $\mathrm{K}$ denotes the strength between the adsorbate and adsorbent. Large values of $\mathrm{K}$ imply more efficient adsorption. ${ }^{27}$

Figure 7 shows Kinetic adsorption isotherm for cellulose acetate where $y$ is the slope of the linear relation between $\log (\theta / 1-\theta)$ vs. $\log$ (C) for all polymers compounds that are reported as shown in Table 3 , if the slope is greater than unity implies the formation of multi-layers of the additive on the metal surface, while if less than unity, however, it means that the given additive molecule occupied more than one active site. Values of $y$ and number of active sites $1 / y$ of the metal surface that occupied by one molecule of the polymer additives under the present conditions have given in Table 4.

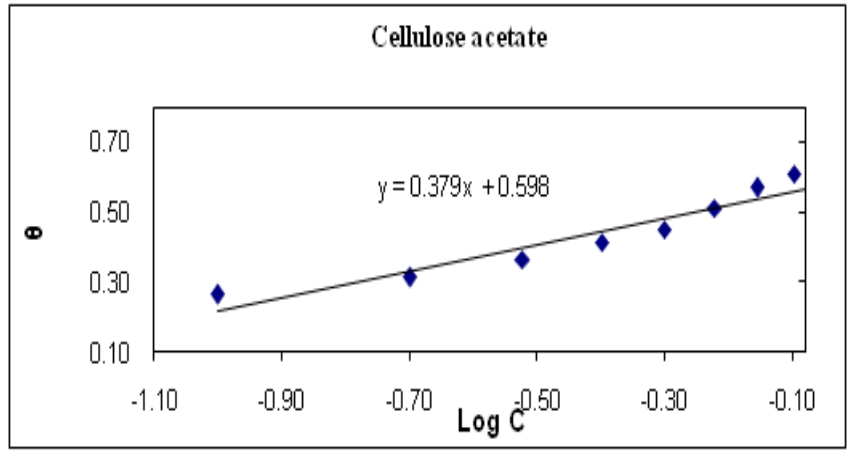

Figure 6 Temkin adsorption isotherms at $298 \mathrm{~K}$ for Cellulose acetate.

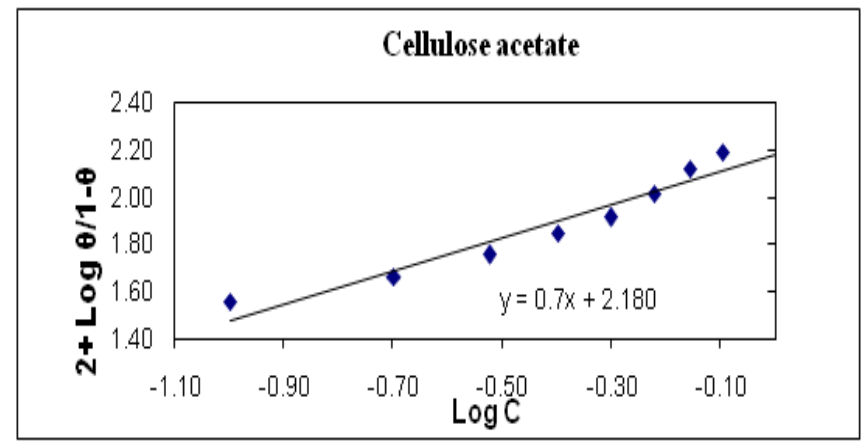

Figure 7 Kinetic adsorption isotherms at 298K for Cellulose acetate.

Obviously, it was concluding from the values in Table 4 that the number of additive molecules which occupy one active site in some cases less than unity and in other cases greater than unity than unity. ${ }^{26,28}$ Also the efficiency of a given inhibitor was essentially a function of the magnitude of its binding constant or the equilibrium constant $\mathrm{K}$, large values of $\mathrm{K}$ indicate better and stronger interaction, whereas small values of $\mathrm{K}$ mean that the interaction between the inhibitor molecules and the metal is weaker. Hence, according to the numerical values of $\mathrm{K}$ as in Table 4, it is observed that the higher value of $\mathrm{K}$ of Cellulose acetate compared to other polymers. This indicate strong adsorption of Cellulose acetate on anodic carbon steel surface and more stable adsorbed layer is formed which increase the inhibition efficiency of Cellulose acetate relative to other polymers. ${ }^{28,29}$ The adsorption of inhibitors at anodic metal surface might be due to the formation of 
either electrostatic (physisorption) or covalent bonding between the inhibitor and metal surface (chemisorptions), ${ }^{30}$ and this depend on the standard free energy of adsorption ( $\Delta$ Goads). The standard free energy change for the adsorption process ( $\Delta$ Goads) for the different inhibitors can be calculated from the following equation: ${ }^{15,31}$

$$
\text { DGoads }=-R T \ln (55.5 \mathrm{~K})
$$

The values of $\Delta$ Goads in case of using undivided cell and divided cell are collected in Table 5. It is clear from Table 5 that the addition of polymers causes negative values of $\Delta$ Goads, which indicate that the polymers molecules are adsorbed spontaneously onto the carbon steel surface in phosphoric acid and there is strong interaction between inhibitors and carbon steel surface which indicated that all inhibitors strongly adsorbed on carbon steel surface. ${ }^{32}$ It is generally accepted that, the values of $\Delta$ Goads are more positive than $-40 \mathrm{~kJ} \mathrm{~mol}^{-1}$ (i.e. the $\Delta$ Goads values are less than $\left.-40 \mathrm{~kJ} \mathrm{~mol}^{-1}\right)$, meaning that the polymers molecules are physically absorbed through electrostatic interactions between the polymers molecules and the metal surface. ${ }^{33}$ The results show that Cellulose acetate, CMC, and Chitosan give maximum efficiency and show more negative free energy of adsorption than other polymers indicating that it is strongly adsorbed on the metal surface. ${ }^{33}$ It is also noticed from Table 5 that the order of decreasing in the standard free energy of adsorption ( $\Delta$ Goads) is as follows:

Cellulose acetate $>(\mathrm{CMC})>$ Chitosan $>$ Cellulose $>$ Arabic gum $>$ Starch $>$ Agar $>$ Gelatin

Table 3 The limiting current and surface coverage in $8 \mathrm{M}$ phosphoric acid with different natural polymers concentrations at $298 \mathrm{~K}$

\begin{tabular}{|c|c|c|c|c|c|c|c|c|c|}
\hline Natural polymers additives & C (ppm) & IL (mA) & $\theta$ & $(I-\theta)$ & $\theta /(\mathbf{I}-\theta)$ & $\log (1-\theta)$ & $\log \theta /(I-\theta)$ & $\log \theta / \mathbf{C}$ & $\log C$ \\
\hline \multirow{8}{*}{ Starch } & 100 & 885 & 0.132 & 0.868 & 0.152 & -0.061 & -0.818 & 0.121 & -1 \\
\hline & 200 & 850 & 0.167 & 0.833 & 0.2 & -0.079 & -0.698 & -0.078 & -0.699 \\
\hline & 300 & 780 & 0.235 & 0.765 & 0.307 & -0.116 & -0.512 & -0.11 & -0.523 \\
\hline & 400 & 700 & 0.314 & 0.686 & 0.458 & -0.164 & -0.339 & -0.105 & -0.398 \\
\hline & 500 & 660 & 0.353 & 0.647 & 0.546 & -0.189 & -0.263 & -0.1512 & -0.301 \\
\hline & 600 & 600 & 0.412 & 0.588 & 0.701 & -0.231 & -0.154 & -0.1632 & -0.222 \\
\hline & 700 & 580 & 0.431 & 0.569 & 0.757 & -0.245 & -0.121 & -0.2106 & -0.155 \\
\hline & 800 & 550 & $0.46 \mathrm{I}$ & 0.539 & 0.855 & -0.268 & -0.068 & -0.2394 & -0.097 \\
\hline \multirow{8}{*}{ Gelatin } & 100 & 950 & 0.069 & 0.931 & 0.074 & -0.031 & -1.13 & -0.1611 & -1 \\
\hline & 200 & 900 & 0.118 & 0.882 & 0.134 & -0.054 & -0.873 & -0.2291 & -0.699 \\
\hline & 300 & 860 & 0.157 & 0.843 & 0.186 & -0.074 & -0.73 & -0.2812 & -0.523 \\
\hline & 400 & 800 & 0.216 & 0.784 & 0.275 & -0.106 & -0.56 & -0.2676 & -0.398 \\
\hline & 500 & 750 & 0.265 & 0.735 & 0.36 & -0.134 & -0.443 & -0.2757 & -0.301 \\
\hline & 600 & 710 & 0.304 & 0.696 & 0.437 & -0.157 & -0.36 & -0.2953 & -0.222 \\
\hline & 700 & 680 & 0.333 & 0.667 & 0.499 & -0.176 & -0.302 & -0.3226 & -0.155 \\
\hline & 800 & 650 & 0.363 & 0.637 & 0.57 & -0.196 & -0.244 & -0.3432 & -0.097 \\
\hline \multirow{8}{*}{ Agar } & 100 & 900 & 0.118 & 0.882 & 0.134 & -0.054 & -0.873 & 0.07188 & -1 \\
\hline & 200 & 840 & 0.176 & 0.824 & 0.213 & -0.084 & -0.67 & -0.0555 & -0.699 \\
\hline & 300 & 800 & 0.216 & 0.784 & 0.275 & -0.106 & -0.56 & -0.1427 & -0.523 \\
\hline & 400 & 750 & 0.265 & 0.735 & 0.36 & -0.134 & -0.443 & -0.1788 & -0.398 \\
\hline & 500 & 700 & 0.314 & 0.686 & 0.458 & -0.164 & -0.339 & -0.202 & -0.301 \\
\hline & 600 & 660 & 0.353 & 0.647 & 0.546 & -0.189 & -0.263 & -0.2304 & -0.222 \\
\hline & 700 & 620 & 0.392 & 0.608 & 0.645 & -0.216 & -0.191 & -0.2518 & -0.155 \\
\hline & 800 & 600 & 0.412 & 0.588 & 0.701 & -0.231 & -0.154 & -0.2882 & -0.097 \\
\hline \multirow{8}{*}{ Chitosan } & 100 & 810 & 0.206 & 0.794 & 0.259 & -0.1 & -0.586 & 0.31387 & -1 \\
\hline & 200 & 760 & 0.255 & 0.745 & 0.342 & -0.128 & -0.466 & 0.10551 & -0.699 \\
\hline & 300 & 690 & 0.323 & 0.677 & 0.477 & -0.169 & -0.321 & 0.03208 & -0.523 \\
\hline & 400 & 645 & 0.368 & 0.632 & 0.582 & -0.199 & -0.235 & -0.0362 & -0.398 \\
\hline & 500 & 585 & 0.426 & 0.574 & 0.742 & $-0.24 I$ & -0.129 & -0.0696 & -0.301 \\
\hline & 600 & 530 & 0.48 & 0.52 & 0.923 & -0.284 & -0.035 & -0.0969 & -0.222 \\
\hline & 700 & 480 & 0.529 & 0.47 I & 1.123 & -0.327 & 0.05 & -0.1216 & -0.155 \\
\hline & 800 & 440 & 0.569 & 0.431 & 1.32 & -0.365 & 0.121 & -0.148 & -0.097 \\
\hline
\end{tabular}


Table Continued.

\begin{tabular}{|c|c|c|c|c|c|c|c|c|c|}
\hline Natural polymers additives & C (ppm) & IL (mA) & $\theta$ & $(I-\theta)$ & $\theta /(I-\theta)$ & $\log (I-\theta)$ & $\log \theta /(I-\theta)$ & $\log \theta / C$ & $\log C$ \\
\hline \multirow{9}{*}{ Arabic gum } & 100 & 870 & 0.147 & 0.853 & 0.172 & -0.069 & -0.764 & 0.16732 & -1 \\
\hline & 200 & 800 & 0.216 & 0.784 & 0.275 & -0.106 & -0.56 & 0.03342 & -0.699 \\
\hline & 300 & 720 & 0.294 & 0.706 & 0.416 & -0.151 & -0.38 & -0.0088 & -0.523 \\
\hline & 400 & 680 & 0.333 & 0.667 & 0.499 & -0.176 & -0.302 & -0.0796 & -0.398 \\
\hline & 500 & 620 & 0.392 & 0.608 & 0.645 & -0.216 & -0.191 & -0.1057 & -0.301 \\
\hline & 600 & 570 & $0.44 I$ & 0.559 & 0.789 & -0.252 & -0.103 & -0.1337 & -0.222 \\
\hline & 700 & 530 & 0.48 & 0.52 & 0.923 & -0.284 & -0.035 & -0.1639 & -0.155 \\
\hline & 800 & 500 & 0.51 & 0.49 & 1.041 & -0.31 & 0.017 & -0.1955 & -0.097 \\
\hline & 100 & 750 & 0.265 & 0.735 & 0.36 & -0.134 & -0.443 & 0.42325 & -1 \\
\hline \multirow{6}{*}{ Cellulose acetate } & 200 & 700 & 0.314 & 0.686 & 0.458 & -0.164 & -0.339 & 0.1959 & -0.699 \\
\hline & 300 & 650 & 0.363 & 0.637 & 0.57 & -0.196 & -0.244 & 0.08279 & -0.523 \\
\hline & 400 & 600 & 0.412 & 0.588 & 0.701 & -0.231 & -0.154 & 0.01284 & -0.398 \\
\hline & 500 & 560 & 0.451 & 0.549 & 0.821 & -0.26 & -0.085 & -0.0448 & -0.301 \\
\hline & 600 & 500 & 0.51 & 0.49 & 1.041 & -0.31 & 0.017 & -0.0706 & -0.222 \\
\hline & 700 & 440 & 0.569 & 0.431 & 1.32 & -0.365 & 0.121 & -0.0899 & -0.155 \\
\hline \multirow{10}{*}{ Cellulose } & 800 & 400 & 0.61 & 0.39 & 1.564 & -0.409 & 0.194 & -0.1178 & -0.097 \\
\hline & 100 & 840 & 0.176 & 0.824 & 0.213 & -0.084 & -0.67 & $0.2455 I$ & -1 \\
\hline & 200 & 790 & 0.225 & 0.775 & 0.29 & -0.111 & -0.537 & 0.05115 & -0.699 \\
\hline & 300 & 700 & 0.314 & 0.686 & 0.458 & -0.164 & -0.339 & 0.01981 & -0.523 \\
\hline & 400 & 650 & 0.363 & 0.637 & 0.57 & -0.196 & -0.244 & -0.0421 & -0.398 \\
\hline & 500 & 600 & 0.412 & 0.588 & 0.701 & -0.231 & -0.154 & $-0.084 I$ & -0.301 \\
\hline & 600 & 540 & $0.47 \mid$ & 0.529 & 0.89 & -0.276 & -0.05 & -0.1051 & -0.222 \\
\hline & 700 & 500 & 0.51 & 0.49 & 1.041 & -0.31 & 0.017 & -0.1375 & -0.155 \\
\hline & 800 & 460 & 0.55 & 0.45 & 1.222 & -0.347 & 0.087 & -0.1627 & -0.097 \\
\hline & 100 & 790 & 0.225 & 0.775 & 0.29 & -0.111 & -0.537 & 0.35218 & -1 \\
\hline \multirow{7}{*}{ Carboxymethyl cellulose } & 200 & 750 & 0.265 & 0.735 & 0.36 & -0.134 & -0.443 & 0.12222 & -0.699 \\
\hline & 300 & 680 & 0.333 & 0.667 & 0.499 & -0.176 & -0.302 & 0.04532 & -0.523 \\
\hline & 400 & 640 & 0.372 & 0.628 & 0.592 & -0.202 & -0.227 & -0.031 & -0.398 \\
\hline & 500 & 575 & 0.436 & 0.564 & 0.773 & -0.249 & -0.112 & -0.059 & -0.301 \\
\hline & 600 & 520 & 0.49 & 0.51 & 0.961 & -0.292 & -0.017 & -0.088 & -0.222 \\
\hline & 700 & 460 & 0.55 & 0.45 & 1.222 & -0.347 & 0.087 & -0.105 & -0.155 \\
\hline & 800 & 410 & 0.598 & 0.402 & I.487 & -0.396 & 0.172 & -0.126 & -0.097 \\
\hline
\end{tabular}

Table 4 Parameters Flory-Huggins, Temkin and kinetic isotherms for polymers at $8 \mathrm{M} \mathrm{H}_{3} \mathrm{PO}_{4}, 3 \mathrm{~cm}$ height and $298 \mathrm{~K}$ in case of using undivided cell

\begin{tabular}{llllllll}
\hline \multirow{2}{*}{ Organic compounds } & \multicolumn{9}{l}{ Models parameters } \\
\cline { 2 - 8 } & \multicolumn{1}{l}{ Temkin } & \multicolumn{3}{c}{ Flory-huggins } & \multicolumn{2}{c}{ Kinetic adsorption isotherm } \\
\cline { 2 - 8 } & $\mathbf{a}$ & $\mathbf{K}$ & $\mathbf{X}$ & $\mathbf{K}$ & $\mathbf{y}$ & $\mathbf{1} \mathbf{y}$ & $\mathbf{K}$ \\
\hline Starch & -1.272 & 16.65 & 1.235 & 1.001 & 0.896 & 1.116 & 1.137 \\
Gelatin & -1.479 & 12.52 & 0.862 & 0.781 & 1.008 & 0.992 & 0.699 \\
Agar & -1.484 & 18 & 1.742 & 0.716 & 0.816 & 1.225 & 0.996 \\
Chitosan & -1.222 & 24.48 & 1.442 & 1.462 & 0.797 & 1.255 & 1.724 \\
Arabic gum & -1.211 & 18.78 & 1.351 & 1.181 & 0.88 & 1.136 & 1.376 \\
Cellulose acetate & -1.319 & 37.83 & 1.639 & 1.813 & 0.7 & 1.429 & 2.162 \\
Cellulose & -1.171 & 20.38 & 1.303 & 1.374 & 0.863 & 1.159 & 1.563 \\
CMC & -1.205 & 25.68 & 1.333 & 1.608 & 0.791 & 1.264 & 1.84 \\
\hline
\end{tabular}

Citation: El-Shamy HF,Aggour YA, Ahmed AM. Study the metallic finishing and corrosion control processes for carbon steel over head pipes using polymer molecules. MOJ Biorg Org Chem. 2017; I (5):I59-168. DOI: 10.15406/mojboc.2017.01.00030 
Table 5 The values of standard free energy of adsorption for polymers using different adsorption isotherms models at $8 \mathrm{M} \mathrm{H}_{3} \mathrm{PO}_{4}, 3 \mathrm{~cm}$ height and $298 \mathrm{~K}$ in case of using undivided cell

\begin{tabular}{|c|c|c|c|}
\hline \multirow{3}{*}{ Natural polymers additives } & \multicolumn{3}{|c|}{$-\Delta$ Goads (K.J. mol-1) } \\
\hline & \multicolumn{3}{|c|}{ Undivided cell } \\
\hline & Temkin & Flory-huggins & Kinetic \\
\hline Starch & 16.92 & 9.95 & 10.27 \\
\hline Gelatin & 16.21 & 9.34 & 9.06 \\
\hline Agar & 17.11 & 9.12 & 9.94 \\
\hline Chitosan & 17.87 & 10.89 & 11.3 \\
\hline Arabic gum & 17.22 & 10.36 & 10.74 \\
\hline Cellulose acetate & 18.95 & 11.42 & 11.86 \\
\hline Cellulose & 17.42 & 10.74 & 11.06 \\
\hline CMC & 17.99 & 11.13 & 11.46 \\
\hline
\end{tabular}

Electropolishing of carbon steel in presence of polymers additives under forced convection mass transfer using rotating cylinder electrode

Table 6 gives the limiting current values at different concentration of polymers additives and different rotation speed at $298 \mathrm{~K}$. We found that the limiting current increases by increasing rotation speed, which indicates that the electropolishing reaction is diffusion controlled reaction and decrease with increasing polymer molecules..$^{33}$

Study the behavior of polymers molecules on carbon steel surface as a corrosion inhibitors using Scanning electron microscope (SEM) examination:

As shown in Figure 8A-8L, the surface morphology before and after electropolishing (EP) of carbon steel in the absence and in the presence of different concentrations of polymers molecules. The SEM analysis Figure 8A shows the morphology of steel before EP. The surface is rough and uneven surface and large number of pits with large size and high depth distributed over the surface are seen. Figure $8 \mathrm{~B}$ after EP with no additive only a slight difference in the surface morphology was observed in which cavities and small pits are represented clearly. Figure $8 \mathrm{C}-8 \mathrm{E}$ show only small change in the morphology of surface with large amount of small pits and deep cavities.

Figure $8 \mathrm{~F}-8 \mathrm{H}$ show very slightly roughness and more homogenous surface. Deep cavities are eliminated by filling up, also, grain boundaries are decreased gradually. This behavior may be due to involvement of Arabic gum, Cellulose and Chitosan molecules in the cavities of steel surface so appear more uniform than blank. Figure 8I \& 8J the metallic surface seems to be almost not affected by corrosion and some precipitates observed. In higher concentration of natural polymers Figure 8K electro polished surface appear uniform, smooth and bright more than Figure $8 \mathrm{C}$ this seems to be due to adsorption of Starch increases. Figure 8L show the SEM images for steel surfaces electro polished at the higher temperatures $(318 \mathrm{~K})$ it shows uniform, smooth and bright surface to some extent more than at lower temperature $(298 \mathrm{~K})$. On other hand in presence of natural polymers there is an improvement in the surface morphology due to decreased in the corroded area caused by the inhibitor layer covering the electrode surface.

\section{Application of polymers additives on corrosion control of carbon steel pipes}

A pilot for distillation tower was used for this application. The overhead of this tower used to release hydrocarbons gases which are corrode the material of this overhead (carbon steel). So many different corrosion inhibitors were injected in this overhead and the efficiency of these corrosion inhibitors were evaluated by measured the Concentration of $\mathrm{Fe}^{+2}(\mathrm{ppm})$ in the sample that taken from a drain system. Concentration of $\mathrm{Fe}^{+2}(\mathrm{ppm})$ in case of presence and absence of polymers molecules were measured using Atomic absorption spectroscopy .we found that as concentration of polymers additives increases, the positively ferrous ions $\mathrm{Fe}^{+2}$ (ppm) will decrease as shown in Table $7 \&$ 9. So this effect will make the ability to control the corrosion in carbon steel and give an indication for these polymers as good inhibitors.

Table 6 Values of limiting current (II) for different concentrations of polymers at $8 \mathrm{M}_{3} \mathrm{PO}_{4}, 3 \mathrm{~cm}$ height, $298 \mathrm{~K}$ and different rotation speeds

\begin{tabular}{|c|c|c|c|c|c|c|c|c|c|c|c|}
\hline Starch & & & & & & Gelatin & & & & & \\
\hline rpm & 100 & 200 & 300 & 500 & 700 & rpm & 100 & 200 & 300 & 500 & 700 \\
\hline C(ppm) & $I_{1}(A)$ & & & & & c (ppm) & $I_{1}(A)$ & & & & \\
\hline 0 & 1.19 & 1.34 & 1.48 & 1.75 & 1.95 & 0 & 1.19 & 1.34 & 1.48 & 1.75 & 1.95 \\
\hline 100 & 1.05 & 1.2 & 1.36 & 1.61 & 1.8 & 100 & 1.13 & 1.27 & 1.42 & 1.69 & 1.89 \\
\hline 200 & 0.98 & 1.14 & 1.3 & 1.56 & 1.75 & 200 & 1.08 & 1.23 & 1.37 & 1.63 & 1.83 \\
\hline 300 & 0.93 & I.I & 1.25 & 1.5 & 1.71 & 300 & 1.04 & 1.17 & 1.3 & 1.57 & I.75 \\
\hline 400 & 0.89 & 1.05 & 1.21 & 1.45 & 1.65 & 400 & 1 & 1.14 & 1.26 & 1.52 & I.7| \\
\hline 500 & 0.85 & 1 & 1.16 & 1.39 & 1.58 & 500 & 0.96 & 1.11 & 1.24 & 1.49 & 1.67 \\
\hline
\end{tabular}


Table Continued.

\begin{tabular}{|c|c|c|c|c|c|c|c|c|c|c|c|}
\hline \multirow{2}{*}{$\begin{array}{l}\text { Starch } \\
\text { rpm }\end{array}$} & \multicolumn{11}{|c|}{ Gelatin } \\
\hline & 100 & 200 & 300 & 500 & 700 & rpm & 100 & 200 & 300 & 500 & 700 \\
\hline $\mathrm{C}(\mathrm{ppm})$ & $I_{1}(A)$ & & & & & c (ppm) & $I_{1}(A)$ & & & & \\
\hline 600 & 0.82 & 0.96 & 1.12 & 1.35 & 1.54 & 600 & 0.93 & 1.07 & 1.2 & 1.45 & 1.64 \\
\hline 700 & 0.78 & 0.92 & 1.06 & 1.3 & 1.5 & 700 & 0.9 & 1.05 & 1.16 & 1.4 & 1.6 \\
\hline 800 & 0.75 & 0.86 & I & 1.25 & 1.46 & 800 & 0.85 & 1.02 & 1.12 & 1.36 & 1.55 \\
\hline Agar & \multicolumn{11}{|c|}{ Chitosan } \\
\hline rpm & 100 & 200 & 300 & 500 & 700 & rpm & 100 & 200 & 300 & 500 & 700 \\
\hline$C(p p m)$ & $I_{1}(A)$ & & & & & $C(p p m)$ & $I_{1}(A)$ & & & & \\
\hline 0 & 1.19 & 1.34 & 1.48 & I.75 & 1.95 & 0 & 1.19 & 1.34 & 1.48 & I.75 & 1.95 \\
\hline 100 & 1.08 & 1.25 & 1.4 & 1.66 & 1.87 & 100 & 0.91 & 1.06 & 1.2 & 1.45 & 1.66 \\
\hline 200 & I.0I & 1.2 & 1.35 & 1.61 & 1.82 & 200 & 0.85 & 1 & 1.15 & 1.4 & 1.57 \\
\hline 300 & 0.96 & 1.14 & 1.28 & 1.55 & 1.73 & 300 & 0.8 & 0.96 & I.I & 1.35 & 1.5 \\
\hline 400 & 0.92 & I.I & 1.24 & 1.5 & I.7I & 400 & 0.77 & 0.9 & 1.03 & 1.3 & 1.45 \\
\hline 500 & 0.89 & 1.04 & 1.2 & $\mathrm{I} .44$ & 1.64 & 500 & 0.74 & 0.83 & 0.97 & 1.25 & 1.39 \\
\hline 600 & 0.85 & 1 & 1.15 & 1.4 & 1.6 & 600 & 0.7 & 0.75 & 0.92 & 1.2 & 1.34 \\
\hline 700 & 0.81 & 0.95 & 1.1 & 1.32 & 1.55 & 700 & 0.66 & 0.7 & 0.86 & 1.16 & 1.3 \\
\hline 800 & 0.78 & 0.9 & 1.05 & 1.25 & 1.5 & 800 & 0.61 & 0.66 & 0.8 & I.I & 1.25 \\
\hline
\end{tabular}

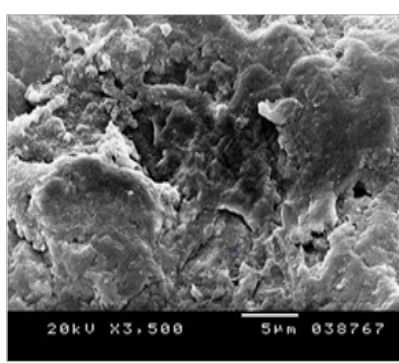

Figure 8A Raw material

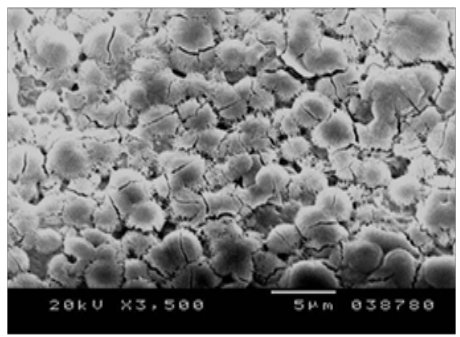

Figure 8D After EP 400ppm Gelatin

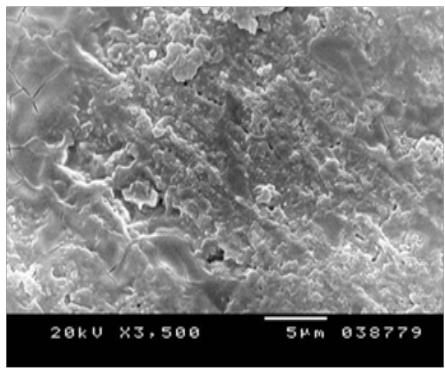

Figure 8G After EP 400ppm Arabic gum

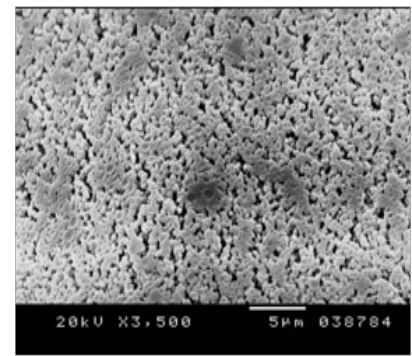

Figure 8B After EP (blank)



Figure 8E After EP 400ppm Agar



Figure 8H After EP 400ppm Cellulose acetate

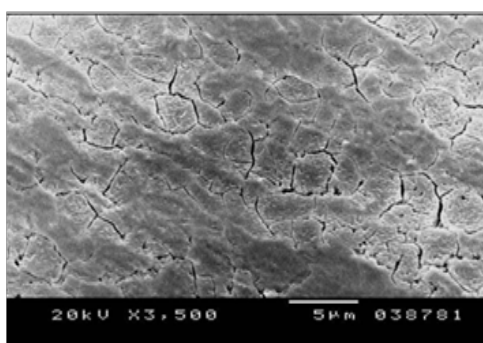

Figure 8C After EP 400ppm Starch



Figure 8F After EP 400ppm Chitosan



Figure 81 After EP 400ppm Cellulose

Citation: El-Shamy HF,Aggour YA,Ahmed AM. Study the metallic finishing and corrosion control processes for carbon steel over head pipes using polymer molecules. MOJ Biorg Org Chem. 20I7; I (5):I59-168. DOI: I0.15406/mojboc.2017.01.00030 




Figure 8J After EP 400ppm CMC

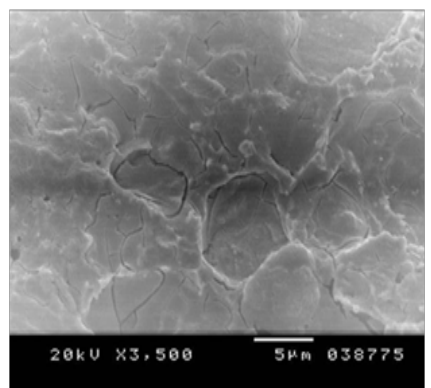

Figure 8K After EP 800ppm Starch

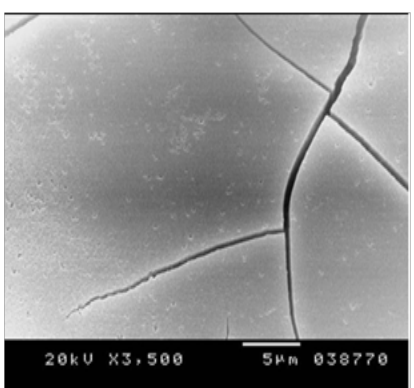

Figure 8L After EP at high temperature (3I8K)

Table 7 Values of $\mathrm{Fe}^{+2}$ (ppm) for different concentrations of polymers additives as corrosion inhibitors at 298K

\begin{tabular}{|c|c|c|c|c|c|c|c|c|}
\hline C (ppm) & \multicolumn{8}{|c|}{$\mathrm{Fe}^{+2} \times 10^{-2}(\mathrm{ppm})$} \\
\hline 0 & 987.4 & 987.4 & 987.4 & 987.4 & 987.4 & 987.4 & 987.4 & 987.4 \\
\hline 100 & 630.6 & 870 & 788.9 & 279.3 & 495.03 & 88.6 & 440.7 & 151.1 \\
\hline 200 & 606.9 & 822.7 & 760.1 & 230.06 & 474.7 & 79.58 & 420.4 & 132.2 \\
\hline 400 & 530.87 & 740.7 & 719.6 & 166.13 & 420.8 & 63.99 & 340.96 & 109.8 \\
\hline 500 & 496.23 & 709 & 697.8 & 134.09 & 398.06 & 55.48 & 299.1 & 100.2 \\
\hline 600 & 450.98 & 688.9 & 670.3 & 110.76 & 360.87 & 46.01 & 270.7 & 90.05 \\
\hline 700 & 410.03 & 634.6 & 605.1 & 90.94 & 290.07 & 35.72 & 219.08 & 70.3 \\
\hline
\end{tabular}

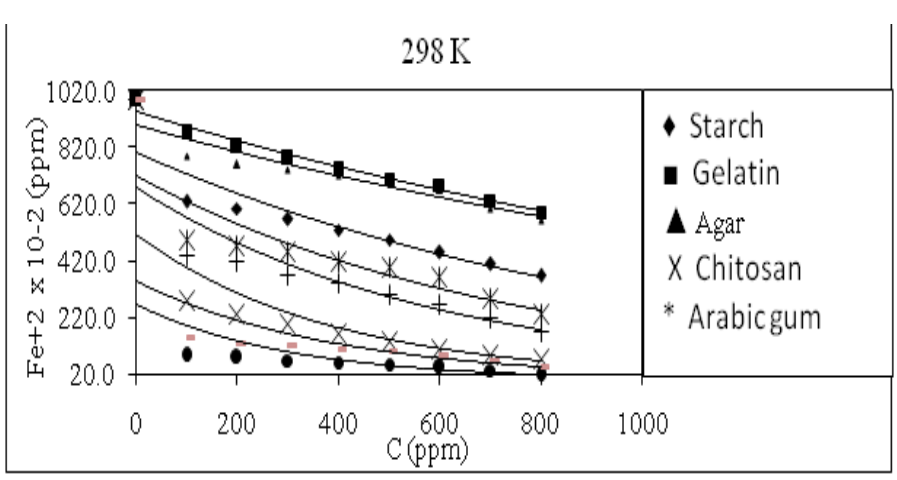

Figure 9 Relation between ferrous ion concentration $\mathrm{Fe}^{+2}(\mathrm{ppm})$ and different concentrations of polymers additives as corrosion inhibitors at $298 \mathrm{~K}$.

\section{Acknowledgements}

None.

\section{Conflict of interest}

The author declares no conflict of interest.

\section{References}

1. Jaquet PA. On the anodic behavior of copper in aqueous solutions of orthophosphoric acid. Trans Electrochem Soc. 1936;69(1):629-655.

2. Shivareddy S, Bae SE, Brankovic SR. Cu Surface Morphology Evolution during Electropolishing. Electrochem Solid-State Lett. 2008;11(1):D13-D17.

3. Burke LD, Sharna R. AC Impedance Investigation of Copper in Acid Solution II. Effect of Bath Additives on Copper Electrodeposition. $J$ Electrochem Soc. 2008;155(4):D285-D297.
4. Wu SP, Jiao L, Ni J, et al. Preparation of ultra fine copper-nickel bimetallic powders for conductive thick film. Intermetallics. 2007;15(10):1316-1321.

5. Sherif EM, Park SM. 2-Amino-5-ethyl-1,3,4-thiadiazole as a corrosion inhibitor for copper in $3.0 \% \mathrm{NaCl}$ solutions. Corros $\mathrm{Sci}$. 2006;48(12):4065-4079.

6. Awad AM, Abdel Ghany NA, Dahy TM. Removal of tarnishing and roughness of copper surface by electropolishing treatment. J Appl Surf Sci. 2010;256(13):4370-4375.

7. Qin TT, Li J, Luo HQ, et al. Corrosion inhibition of copper by 2,5dimercapto-1,3,4-thiadiazole monolayer in acidic solution. Corros Sci. 2011;53(3):1072-1078.

8. Revised Draft SGEIS on the Oil, Gas and Solution Mining Regulatory Program. Chemical Categories and Health Information. USA; 2011. 8

9. Ateya BG, EL-Anadouli BE, EL-Nizamy FM. The adsorption of thiourea on mild steel. Corros Sci. 1984;24(6):509-515.

10. Abd El-Wanees S, Abd El-Aal EE. N-Phenylcinnamimide and some of its derivatives as inhibitors for corrosion of lead in $\mathrm{HCl}$ solutions. Corros Sci. 2010;52(2):338-344.

11. Jia-Jun F, Li Sn, Wang Y, et al. Computational and electrochemical studies of some amino acid compounds as corrosion inhibitors for mild steel in hydrochloric acid solution. J Mater Sci. 2010;46(22):62556265 .

12. Da Rocha JC, Gomes DCP, D'Elia E. Corrosion inhibition of carbon steel in hydrochloric acid solution by fruit peel aqueous extracts. Corros Sci. 2010;52(7):2341-2348.

13. Saliyan VR, Adhikari AV. Inhibition of corrosion of mild steel in acid media by N'-benzylidene-3-(quinolin-4-ylthio) propanohydrazide. Bull Mater Sci. 2008;31(4):699-711. 
14. Taha AA, Ahmed AM, Abdel Rahman HH, et al. The effect of surfactants on the electropolishing behavior of copper in orthophosphoric acid. Appl Surf Sci. 2013;277:155-166.

15. Yaro AS, Khadom AA, Ibraheem HF. Peach juice as an anti-corrosion inhibitor of mild steel. Anti-Corros Methods Mater. 2011;58(3):116124

16. Juuti T, Uusikallio V, Kaijalainen AJ, et al. The Effect of Sample Preparation on The Microstructure of Austenitic-Ferritic Stainless Steel. Materials Science Forum. 2017;879:873-878.

17. Alykov NM, Tyrkov AG, Pichugina EA, et al. Inhibitors of acidic corrosion for protection of oil and gas pipelines. RU patent 2365679 , Russia; 2009.

18. MacDonald DD, Roberts B, Hyne JB. The corrosion of carbon steel by wet elemental sulphur. Corrosion Science. 1987;18(5):411-425.

19. Mounir F, Issami S El, Bazzi Lh, et al. Copper Corrosion Behavior in Phosp Horic Acid Containing Chloride and its Inhibition by Artemisia Oil. Int J Res Rev Appl Sci. 2012;13(2):574-587.

20. Shaker MA, Abdel Rahman HH. Corrosion of copper metal in presence of binary mixtures. Am J Appl Sci. 2007;4(8):554-564.

21. Ketsetzi A, Stathoulopoulou A, Demadis KD. Being "green" in chemical water treatment technologies: issues, challenges and developments. Desalination. 2008;223(1-3):487-493.

22. Akalezi CO, Enenebaku CK, Oguzie EE. Application of aqueous extracts of coffee senna for control of mild steel corrosion in acidic environments. Int J Ind Chem. 2012;3(1):1-13.

23. Soliman HMA, Abdel Rahman HH. The use of rotating cylinder electrode to study the effect of 1,3-dihydroxypropane on the production of copper powder. J Brazil Chem Soc. 2006;17(4):705-714.
24. El-Subruiti GM, Ahmed AM, Koretam MG. Kinetics and thermodynamic studies of dissolution of copper plates in presence of amino compounds. Bull Electrochem. 2003;19(4):185-192.

25. Shaker MA, Abdel Rahman HH. Corrosion of Copper Metal in Presence of Binary Mixtures. Am J Appl Sci. 2007;4(8):554-564.

26. Moretti G, Guidi F. Tryptophan as copper corrosion inhibitor in $0.5 \mathrm{M}$ aerated sulfuric acid. Corros Sci. 2002;44(9):1995-2011.

27. Shah M, Rahim AA, Hamid SA, et al. Green Inhibitors for Copper Corrosion by Mangrove Tannin. Int J Electrochem Sci. 2013;8:2140 2153.

28. Ayobe EA, Abaza SF, Seleim SM, et al. Anodic corrosion of copper in presence of aniline derivatives. Indian J Chem Technol. 2012;19:322330.

29. Awizar DA, Othman NK, Jalar A, et al. Nanosilicate Extraction from Rice Husk Ash as Green Corrosion Inhibitor. Int J Electrochem Sci. 2013;8:1759-1769.

30. Mistry BM, Patel NS, Sahoo S, et al. Experimental and quantum chemical studies on corrosion inhibition performance of quinoline derivatives for MS in 1N HCl. Bull Mater Sci. 2012;35(3):459-469.

31. Abdel Rahman HH, Moustafa AHE, Awad MK. Potentiodynamic and Quantum Studies of Some Amino Acids as Corrosion Inhibitors for Copper. Int J Electrochem Sci. 2012;7:1266-1287.

32. Ahmed AM, Abd El-Haleem SM, Darweesh MM, et al. Corrosion of copper in presence of aromatic acids. Bull Electrochem. 2003;19(11):489-504.

33. El-Mallah NM, AM Ahmed, LF Gado. Electrodeposition of Copper in Presence of Carbohydrates. J Dispers Sci Technol. 2010;31(11):1579_ 1590 . 